\title{
Acute tubulointerstitial nephritis following aciclovir treatment for chickenpox in children with nephrotic syndrome - a report of two cases
}

\author{
MAEGORZATA PAŃCZYK-TOMASZEWSKA', ELŻBIETA KUŹMA-MROCZKOWSKA', \\ PIOTR SKRZYPCZYK ${ }^{1}$, HANNA SZYMANIK-GRZELAK ${ }^{1}, J A D W I G A ~ M A E D Y K^{2}$
}

${ }^{1}$ Department of Pediatrics and Nephrology, Medical University of Warsaw, Warsaw, Poland

${ }^{2}$ Department of Pathology, Medical University of Warsaw, Warsaw, Poland

\begin{abstract}
Tubulointerstitial nephritis (TIN) is an inflammatory process primarily involving the renal interstitium and is the cause of acute kidney injury (AKI) in 3-7\% of cases confirmed by renal biopsy in children. Aciclovir may have a nephrotoxic effect by crystallization in renal tubules or by inducing an immunologic process that leads to development of TIN.

We report 2 male patients, aged 10 and 8 years, with nephrotic syndrome (NS), in whom disease relapse was triggered by varicella zoster infection. The patients received intravenous aciclovir which resulted in AKI due to acute TIN with the glomerular filtration rate 19.5 and $24.9 \mathrm{ml} / \mathrm{min} / 1.73 \mathrm{~m}^{2}$, respectively. The diagnosis was confirmed by kidney biopsy in one of these patients. Initiation of glucocorticosteroids and withdrawal of aciclovir resulted in resolution of proteinuria and symptoms of AKI.

In children with active NS treated with intravenous aciclovir, a possibility of AKI due to TIN should be taken into account.
\end{abstract}

Key words: children, nephrotic syndrome (NS), acute tubulointerstitial nephritis (TIN), acyclovir.

(Centr Eur J Immunol 2020; 45 (4): 494-497)

\section{Introduction}

Tubulointerstitial nephritis (TIN) is an inflammatory process which primarily involves the renal interstitium. It is caused by toxic agents or microorganisms. The most common cause of TIN, present in as many as $70 \%$ cases, is an immunological/allergic response to non-steroidal anti-inflammatory drugs, antibiotics, and antiviral drugs. It may also develop secondarily to glomerular or renal vascular damage. Based on the duration of symptoms, TIN is categorized as acute or chronic (the latter with symptoms for $\geq 3$ months). TIN usually manifests with acute kidney injury (AKI) with evidence of tubular damage. It may also be accompanied by systemic symptoms and signs including abdominal pain, vomiting, skin rash, and fever. TIN is the cause of AKI in $27 \%$ of cases in adults, and of $3-7 \%$ of cases confirmed by biopsy in children [1-3].

Varicella zoster infection may have a very severe course in patients with nephrotic syndrome (NS), in rare cases leading even to death [4]. Kidney Disease: Improving Global Outcomes guidelines encourage vaccination of NS patients with life varicella vaccine. However, vaccination is contraindicated while on immunosuppressive or cytotoxic agents, and should be deferred until the predni- sone dose is below $20 \mathrm{mg} /$ day and/or immunosuppressive agents have been stopped for at least 1-3 months [5]. Also, following close contact with varicella infection, nonimmune children with NS treated with immunosuppressive agents ought to be given varicella zoster immune globulin. And once chicken pox lesions appear, the child should be started on aciclovir or valaciclovir.

We report 2 patients in whom symptoms of AKI due to TIN following aciclovir therapy were associated with recurrent NS.

\section{Case reports}

\section{Patient 1}

A 10-year-old boy was admitted due to a relapse of NS related to chickenpox. The patient had steroid-sensitive NS since 4 years of age and had suffered six relapses of NS. Glucocorticosteroid (GCS) therapy was discontinued 1.5 years earlier. The patient had not been vaccinated against varicella zoster virus. On admission, the patient presented with generalized edema and chickenpox rash, and laboratory tests showed nephrotic range proteinuria of $1000 \mathrm{mg} / \mathrm{dl}$ (daily urinary collection - $66 \mathrm{mg} / \mathrm{kg} / 24 \mathrm{~h}$ ),

Correspondence: Malgorzata Pańczyk-Tomaszewska, MD, PhD, Department of Pediatrics and Nephrology Medical University of Warsaw, e-mail: mpanczyk1@wum.edu.pl

Submitted: 21.04.2020; Accepted: 07.07.2020 
Table 1. Laboratory test results in the studied children with nephrotic syndrome and acute kidney injury

\begin{tabular}{|c|c|c|c|c|c|c|c|c|c|}
\hline & $\begin{array}{l}\text { Creatinine } \\
{[\mathrm{mg} / \mathrm{dl}]}\end{array}$ & $\begin{array}{l}\text { Urea } \\
{[\mathrm{mg} / \mathrm{dl}]}\end{array}$ & $\begin{array}{l}\text { GFR acc. to Schwartz } \\
{\left[\mathrm{ml} / \mathrm{min} / 1.73 \mathrm{~m}^{2}\right][19]}\end{array}$ & $\begin{array}{c}\mathbf{H b} \\
{[\mathrm{g} / \mathrm{dl}]}\end{array}$ & $\begin{array}{l}\text { WBC } \\
{\left[10^{3} / \mu \mathrm{l}\right]}\end{array}$ & $\begin{array}{c}\text { Platelets } \\
{\left[10^{3} / \mu \mathrm{I}\right]}\end{array}$ & $\begin{array}{c}\text { CRP } \\
{[\mathrm{mg} / \mathrm{dl}]}\end{array}$ & $\begin{array}{l}\text { Albumin } \\
\text { [g/dl] }\end{array}$ & $\begin{array}{c}\text { Proteinuria } \\
\text { [mg/dl }]\end{array}$ \\
\hline \multicolumn{10}{|c|}{ Patient 1} \\
\hline Day 1 & 0.5 & 30 & 120.6 & 11.4 & 11 & 280 & $<0.5$ & 2.2 & 1000 \\
\hline Day 2 & 3.1 & 108 & 19.5 & 11.5 & 10 & 269 & $<0.5$ & 3.2 & 800 \\
\hline Day 4 & 2.5 & 106 & 24.0 & 11.4 & 13.2 & 338 & $<0.5$ & 3.1 & 300 \\
\hline Day 9 & 0.6 & 22 & 100.5 & 12.6 & 24.8 & 617 & $<0.5$ & 3.3 & 0 \\
\hline Day 13 & 0.4 & 16 & 150.7 & 13.4 & 24.5 & 548 & $<0.5$ & 4.0 & 0 \\
\hline \multicolumn{10}{|c|}{ Patient 2} \\
\hline Day 1 & 0.4 & 12 & 130.6 & 15.9 & 5.9 & 281 & $<0.5$ & 3.2 & 519 \\
\hline Day 3 & 2.1 & 66 & 24.9 & 16.1 & 10.1 & 312 & $<0.5$ & 3.1 & 300 \\
\hline Day 6 & 0.6 & 37 & 87.1 & 16.2 & 5.64 & 406 & $<0.5$ & 3.8 & 0 \\
\hline
\end{tabular}

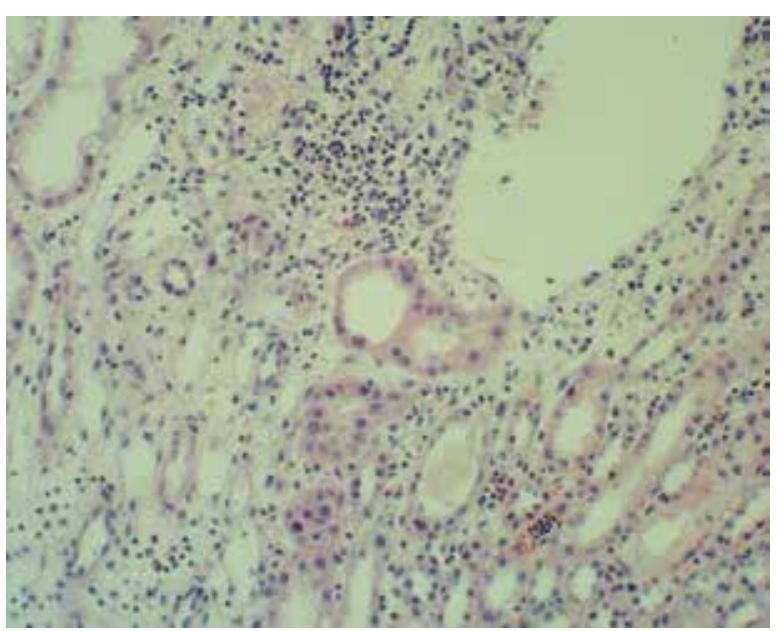

Fig. 1. Renal biopsy findings, hematoxylin and eosin, 200x

serum albumin level of $2.2 \mathrm{~g} / \mathrm{dl}$, serum creatinine level of $0.5 \mathrm{mg} / \mathrm{dl}$, cholesterol level $-176 \mathrm{mg} / \mathrm{dl}$, and triglycerides $-186 \mathrm{mg} / \mathrm{dl}$. Therapy included aciclovir at a standard dose. In addition, the patient received twice $100 \mathrm{ml} 20 \%$ albumin infusion, furosemide and hydrochlorothiazide. On the second day of treatment, the patient presented with abdominal pain, nausea, vomiting, and hypertension (133/82 $\mathrm{mmHg}$ ). Laboratory tests showed evidence of AKI (Table 1), and urinalysis revealed persisting proteinuria of $800 \mathrm{mg} / \mathrm{dl}$, with no changes in urine sediment (1-2 leukocytes, 3-4 erythrocytes per field of view). In immunological studies, white blood cell count was $10.0 \times 10^{3} / \mu \mathrm{l}$, lymphocyte count $1.6 \times 10^{3} / \mu \mathrm{l}$, neutrophil count $7.2 \times 10^{3} / \mu \mathrm{l}$, monocyte count $1.0 \times 10^{3} / \mu \mathrm{l}$; C3 $100 \mathrm{mg} / \mathrm{dl}$ (n: 88-201), C4 $19.5 \mathrm{mg} /$ dl (n: 16-47), antinuclear and antineutrophil cytoplasm antibodies were negative; also negative hepatitis serology (antiHBs $15.4 \mathrm{mIU} / \mathrm{ml}$, negative HBs antigen and antiHCV antibodies). Ultrasound showed enlarged, hyperechogenic kidneys with reduced parenchymal perfusion. Aciclovir was discontinued. Kidney needle biopsy performed on the fourth day showed interstitial inflammatory foci with lymphocytes and single eosinophils, and heterogeneously increased cellularity and mesangial matrix within the glomeruli (Fig. 1). Acute TIN in a patient with idiopathic NS was diagnosed. Prednisone $1 \mathrm{mg} / \mathrm{kg} / \mathrm{day}$ was initiated on the fourth day. Renal function and blood pressure normalized after 5 days of treatment, with resolution of proteinuria. Prednisone treatment was continued for 6 months.

\section{Patient 2}

An 8-year-old boy was admitted due to recurrent NS related to chickenpox. The patient had steroid-sensitive NS since 2 years of age and had suffered nine relapses of NS. He had been previously treated with prednisone, methylprednisolone pulses ( 8 pulses during treatment of the fifth disease relapse), cyclophosphamide, and chlorambucil. The patient had not received varicella zoster vaccination either. The patient was also diagnosed with renovascular hypertension, with computed tomography angiography showing dual arterial supply to both kidneys and a stenosis of the accessory right renal artery. On admission, the patient was treated with prednisone $1.25 \mathrm{mg} / \mathrm{kg} / 48$ hours and the antihypertensive drugs amlodipine and enalapril. Initially, the patient also presented with mild generalized edema and chickenpox rash, normal diuresis and well-controlled hypertension. Nephrotic range proteinuria of $519 \mathrm{mg} / \mathrm{dl}$ was found but without full laboratory criteria of an NS relapse (Table 1). Initial treatment included previous prednisone dose daily and intravenous aciclovir at a standard dose. On the third day of treatment, the patient presented with abdominal pain and increasing parameters of renal dysfunction (Table 1). In immunological studies, white blood cell count was $10.1 \times 10^{3} / \mu \mathrm{l}$, lymphocyte count $3.2 \times 10^{3} / \mu \mathrm{l}$, neutrophil count $5.7 \times 10^{3} / \mu \mathrm{l}$, monocyte count $1.2 \times 10^{3} / \mu \mathrm{l}$; there was normal IgM 112 mg/dl (n: 36-198), lowered IgG 269 mg/dl 
(n: 853-1440), normal IgA 75.4 mg/dl (n: 38-235), normal C3 121 mg/dl (n: 88-201), C4 $20.1 \mathrm{mg} / \mathrm{dl}$ (n: 16-47) concentrations, antinuclear and antineutrophil cytoplasm antibodies were negative; also negative hepatitis serology (antiHBs $22.2 \mathrm{mIU} / \mathrm{ml}$, negative $\mathrm{HBs}$ antigen and antiHCV antibodies), and CMV (IgM $0.08-\mathrm{n}:<0.7, \operatorname{IgM}<4-\mathrm{n}:<4 \mathrm{UA} / \mathrm{ml}$ ) and EBV serology (EBV VCA IgM $0.05-<0.11$, VCA/ EA IgG $0.81-\mathrm{n}:<0.09$, EBNA IgG $-0.00 \mathrm{n}:<0.09)$ were found. Urinalysis showed persistent proteinuria at $300 \mathrm{mg} / \mathrm{dl}$ and 6-10 leukocytes per field of view. Ultrasound revealed enlarged, hyperechogenic kidneys. As acute TIN related to aciclovir treatment was suspected, aciclovir was discontinued and the prednisone dose was increased to $60 \mathrm{mg}$ per day. Resolution of proteinuria and normalization of renal function were seen on the sixth day of hospital stay.

\section{Discussion}

In both reported patients with NS, the primary reason for admission was a recurrence of nephrotic range proteinuria associated with chickenpox. On admission, both patients had normal renal function. Antiviral treatment with aciclovir was initiated due to an active varicella-zoster virus infection, recurrence of proteinuria, and GCS treatment (patient 1). At 2-3 days of aciclovir treatment, both boys presented with abdominal pain and AKI.

The occurrence of AKI in children with NS is rare. In the study by Pstrusińska et al., AKI was noted in 8/1006 children $(0.8 \%)$ with NS aged 6 to 17.5 years [6]. AKI may result from hypovolemia, tubular necrosis, bilateral renal vein thrombosis, acute pyelonephritis, rapidly progressive glomerular disease, and TIN [7]. A high prevalence (27\%) of TIN as the cause of AKI in adults, and much lower in children (3-7\%), warrants considering this entity in the differential diagnosis of AKI [8].

Single case reports of TIN in children with active NS are available in the literature. In some cases, due to concomitant treatment with multiple medications, it is difficult to identify the agent that induced an immunologic reaction. In one case, the patient received amoxicillin, paracetamol, furosemide, and a herbal preparation [7], and another patient was treated with ciclosporin and amoxicillin-clavulanate [9]. In a third reported case, the authors associated TIN with intravenous immune globulin therapy [10].

In our patients, due to a temporal association between symptoms and administration of aciclovir, with no other causes of renal failure such as hypovolemia and thrombotic or infective complications, a possibility of a toxic effect of aciclovir was considered in the first place. Nephrotoxicity of aciclovir has been well documented [11, 12]. The drug impairs renal function by crystallization in renal tubules, particularly in patients with hypovolemia [13, 14]. In an analysis by Rao et al., glomerular filtration rate (GFR) reduction was noted in $35 \%$ (131/373) of children treated with intravenous aciclovir. Using the RIFLE score modified for the pediatric population (eGFR reduction by $25-49 \%$ defines risk, by $50-74 \%$ defines renal injury, and by $<75 \%$ defines renal failure), risk was found in 81 of $373(22 \%)$ treated children, injury in 36 of $373(9.7 \%)$ children, and renal failure in 14 of $373(3.8 \%)$ children. This analysis showed that the risk of nephrotoxicity was higher in children treated with higher drug doses, aged $>8$ years, with high body mass index, and receiving concomitant ceftriaxone treatment [15]. Aciclovir may also have a nephrotoxic effect by inducing an immunologic process that leads to development of TIN $[11,12,16]$. The disease manifests with proteinuria, renal dysfunction, leukocyturia, erythrocyturia, eosinophiluria, eosinophilia, and systemic symptoms and signs including fever, abdominal pain, rash, and arthralgia. Proteinuria is usually mild but may also be in the nephrotic range and lead to clinical and laboratory manifestations of NS [3, 17].

In our patients, AKI was superimposed on active NS. In patient 1 , the diagnosis of TIN was confirmed by kidney biopsy. In addition, electron microscopy showed podocyte foot process fusion. Kidney biopsy was not performed in patient 2. In another case reported in the literature, TIN preceded NS in a child, and biopsy confirmed lesions typical for both conditions [18]. In our paper, we reported two cases of AKI due to TIN following aciclovir treatment which were superimposed on active NS. In both these patients, prompt diagnosis of TIN, discontinuation of aciclovir, and treatment with GCS led to rapid normalization of renal function and rapid remission of NS.

\section{Conclusions}

In children with active NS treated with intravenous aciclovir, a possibility of AKI due to TIN should be taken into account.

\section{The authors declare no conflict of interest.}

\section{References}

1. Raghavan R, Eknoyan G (2014): Acute interstitial nephritis a reappraisal and update. Clin Nephrol 82: 149-162.

2. Ulinski T, Sellier-Leclerc AL, Tudorache E, et al. (2012): Acute tubulointerstitial nephritis. Pediatr Nephrol 27: 1051-1057.

3. Joyce E, Glasner P, Ranganathan S, et al. (2017): Tubulointersitial nephritis: diagnosis, treatment, and monitoring. Pediatr Nephrol 32: 577-587.

4. Gangaram HB, Cheong IK (1993): Fatal haemorrhagic chickenpox complicating nephrotic syndrome. Med J Malaysia 48: 446-448.

5. Cattran DC, Feehally J, Cook HT (2012): Kidney disease: improving global outcomes (KDIGO) glomerulonephritis work group: KDIGO clinical practice guideline for glomerulonephritis. Kidney Int Suppl 2: 139-274.

6. Kilis-Pstrusinska K, Zwolinska D, Musial K (2000): Acute renal failure in children with idiopathic nephrotic syndrome. Pol Merkur Lekarski 8: 462-464. 
7. Agarwal N, Phadke KD, Garg I, et al. (2003): Acute renal failure in children with idiopathic nephrotic syndrome. Pediatr Nephrol 18: 1289-1292.

8. Praga M, Gonzalez E (2010): Acute interstitial nephritis. Kidney Int 77: 956-961.

9. Printza N, Koukourgianni F, Saleh T, et al. (2009): Druginduced interstitial nephritis in a child with idiopathic nephrotic syndrome. Saudi J Kidney Dis Transpl 20: 1072-1075.

10. Tanaka H, Waga S, Tateyama T, et al. (1999): Acute tubulointerstitial nephritis following intravenous immunoglobulin therapy in a male infant with minimal-change nephrotic syndrome. Tohoku J Exp Med 189: 155-161.

11. Patzer L (2008): Nephrotoxicity as a cause of acute kidney injury in children. Pediatr Nephrol 23: 2159-2173.

12. Krishnan N, Perazella MA (2015): Drug-induced acute interstitial nephritis: pathology, pathogenesis, and treatment. Iran J Kidney Dis 9: 3-13.

13. Seedat A, Winnett G (2012): Acyclovir-induced acute renal failure and the importance of an expanding waist line. BMJ Case Rep 2012: bcr2012006264.

14. Pela I, Micheletti MV (2010): Acute kidney injury in a child with MCNS during cyclosporine A and acyclovir treatment. Clin Exp Nephrol 14: 645-646.

15. Rao S, Abzug MJ, Carosone-Link P, et al. (2015): Intravenous acyclovir and renal dysfunction in children: a matched case control study. J Pediatr 166: 1462-1468.

16. Rashed A, Azadeh B, Abu Romeh SH (1990): Acyclovirinduced acute tubulo-interstitial nephritis. Nephron 56: 436438.

17. Dharnidharka VR, Rosen S, Somers MJ (1998): Acute interstitial nephritis presenting as presumed minimal change nephrotic syndrome. Pediatr Nephrol 12: 576-578.

18. Takahashi S, Kitamura T, Murakami H, et al. (2005): Acute interstitial nephritis predisposed a six-year-old girl to minimal change nephrotic syndrome. Pediatr Nephrol 20: 1168-1170.

19. Schwartz GJ, Muńoz A, Schneider MF, et al. (2009): New equations to estimate GFR in children with CKD. J Am Soc Nephrol 20: 629-637. 